THE RING 34 (2012) DOI 10.2478/v10050-012-0004-1

\title{
COMPARABILITY OF WING LENGTH MEASUREMENTS BASED ON DATA COLLECTED AT TWO TWIN STATIONS DURING MIGRATION
}

\author{
Grzegorz Zaniewicz
}

\begin{abstract}
Zaniewicz G. 2012. Comparability of wing length measurements based on data collected at two twin stations during migration. Ring 34: 37-43.

Data collected during bird migration include measurements taken during ringing. The variety and quality of information, which these measurements can potentially provide, depend strongly on their accuracy and comparability.

The analysis of the comparability was made based on the measurements of wing length taken by different ringers during autumn migratory seasons at the southern Baltic coast. An experiment was run with the measurements taken from six passerine species during several (from 8 to 10 , depending on the species) migratory seasons at two twin sites belonging to Mierzeja Wiślana station. Pearson's correlation coefficient was used to evaluate how strongly the habits of different measurers influence the measurements taken. The results of this experiment show that correlations between the measurements collected at these two sites are strong and statistically significant for the Blackcap (Sylvia atricapilla), Garden Warbler (Sylvia borin), Robin (Erithacus rubecula) and Song Thrush (Turdus philomelos). However, for the Goldcrest (Regulus regulus) and Willow Warbler (Phylloscopus trochilus) the relations were not significant. The last species allow to consider other causes, independent from human factor, which are possibly responsible for the average wing length local variability. In such species, we still need to look closer at the potential sources of their differentiation, such as the preferences of habitat selection between sexes, populations, etc.
\end{abstract}

G. Zaniewicz, Bird Migration Research Foundation, Przebendowo, PL-84-210 Choczewo, Poland; Bird Migration Research Station, Wita Stwosza 59, PL-80-308 Gdańsk, Poland, E-mail: zidia@wp.pl

Publication appointed to the SE European Bird Migration Network papers

Key words: wing length measurement, personal bias, migration

\section{INTRODUCTION}

The length of the wing is the most common measurement taken during ornithological studies. Three different techniques of the wing length measurement are used (Svensson 1992, Gosler et al. 1995), which unfortunately precludes a direct compari- 
son between data collected at some stations. Relatively simple techniques of measuring the wing length compared to the tail length or wing formula, allow to collect data useful for various studies concerning long-term changes, climate changes, populations, sex and age differentiation, adaptation for migration, timing of migration (e.g. Busse 1968, 1988, 1997, 1999; Busse and Maksalon 1986; Lo Valvo et al. 1988; Tellería and Carbonell 1999; Nowakowski 2000, 2002; Pèrez-Tris and Tellería 2001, 2002; Yom-Tov et al. 2006; Zaniewicz and Busse 2008; Salewski et al. 2010; Van Buskirk et al. 2010; Kovács et al. 2010, 2012; Arizaga et al. 2012). However, clear dependencies are usually hidden, as the variation in wing length depends on several factors, such as sex, age, population, status of the specimen (skin, live bird) (Svensson 1992, Jenni and Winkler 1994, Fiedler 2005). Some additional variation is also caused by different habits of individual ringers who take measurements (Barrett et al. 1989, Morgan 2004). It is also confirmed, that the repeatability of wing length measurements between two or more measurers is lower than it is in the case of an individual measurer (Harper 1994). This study is an attempt to establish the level of comparability for different measurers who collected data independently on the same migration route.

\section{STUDY AREA AND MATERIAL}

Mierzeja Wiślana $\left(54^{\circ} 21^{\prime} \mathrm{N}, 1^{\circ} 19^{\prime} \mathrm{E}\right.$; Fig. 1). Migrants were captured in the mistnets and, in some years, additionally in the Heligoland-type trap. Two main capturing sites (named here as MW and ML) were located on the Vistula Spit in young pine stands and older stands mixed with oaks as well as in reedbeds surrounding the Vistula Lagoon (for detailed description see Busse and Kania 1970). The numbers of birds caught at both sites in particular seasons of study are given in Table 1.

\section{METHODS}

\section{Fieldwork}

A stable number of the mist-nets were used throughout the whole period of work within a season. Captured individuals were ringed, sexed (when possible) and aged according to plumage features and/or skull ossification (Busse 1984). A detailed description of the field methods was given by Busse and Kania (1970) and Busse (1984, 2000).

\section{Wing length measurement}

The maximum chord measurement was used - detailed description was given by Busse $(1974,2000)$ - with the accuracy of $1 \mathrm{~mm}$. The wing length measurements were taken by different ringers during the analysed period of the study. The measurements taken into the analysis included only first year individuals (immatures) representing six passerine species: Blackcap (Sylvia atricapilla), Garden Warbler ( $S$. borin), Robin (Erithacus rubecula), Song Thrush (Turdus philomelos), Goldcrest (Regulus regulus) and Willow Warbler (Phylloscopus trochilus), for which the data were sufficient enough to run statistical analysis (at least 20 individuals per season). 


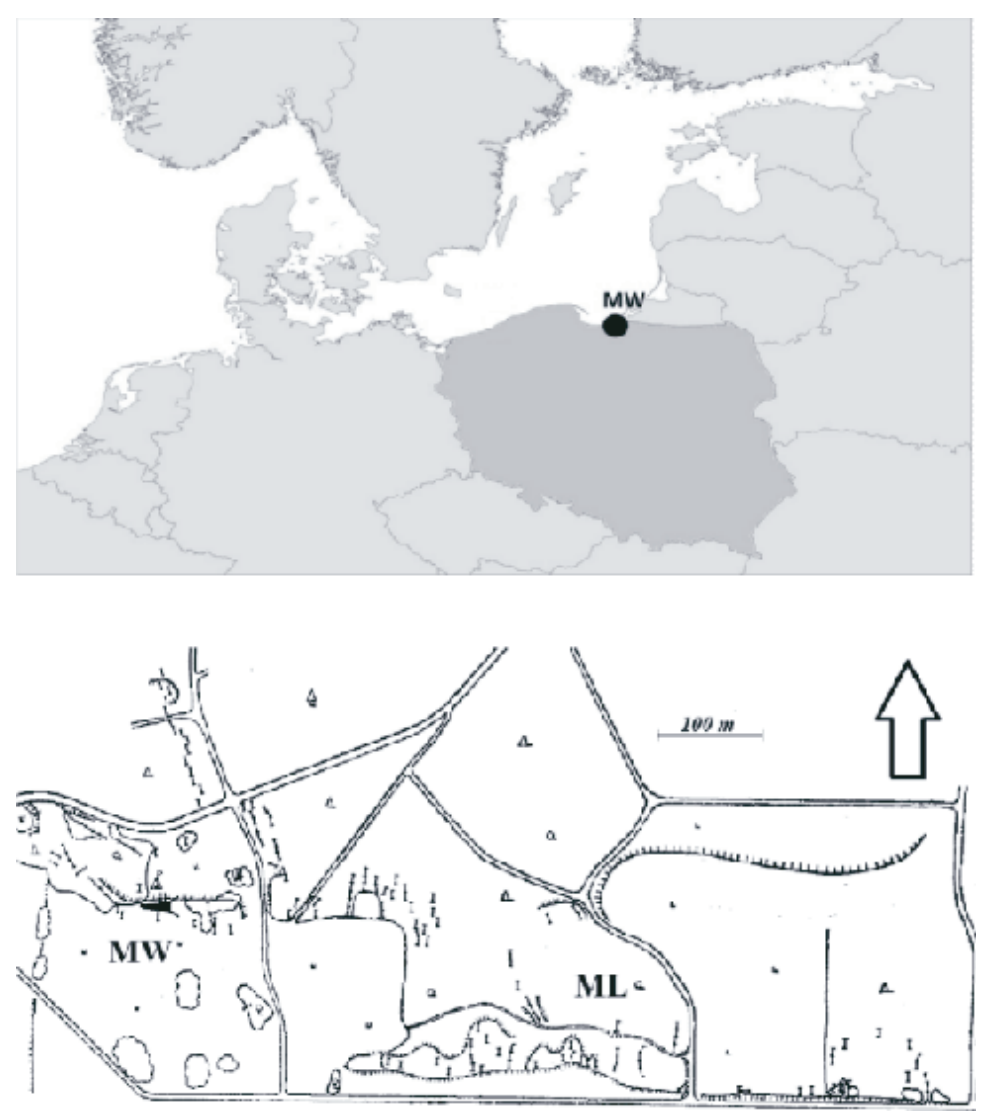

Fig. 1. Location of Mierzeja Wiślana ringing station (above) and a map of two sub-stations - MW and ML (below); after Busse and Kania 1970.

Table 1

Numbers of measured individuals

\begin{tabular}{|c|c|c|c|c|c|c|c|c|c|c|c|c|}
\hline & Site & 1967 & 1968 & 1969 & 1971 & 1972 & 1973 & 1974 & 1981 & 1982 & 1983 & Total \\
\hline \multirow{2}{*}{$\begin{array}{l}\text { Sylvia } \\
\text { atricapilla }\end{array}$} & MW & 60 & 70 & 72 & 74 & 48 & 35 & 43 & 39 & 32 & 30 & 503 \\
\hline & ML & 84 & 6 & 144 & 127 & 84 & 143 & 156 & 103 & 75 & 23 & 1035 \\
\hline \multirow{2}{*}{$\begin{array}{l}\text { Sylvia } \\
\text { borin }\end{array}$} & MW & 40 & 38 & 29 & 42 & 90 & 30 & 21 & 60 & 28 & - & 378 \\
\hline & ML & 106 & 115 & 97 & 45 & 107 & 68 & 124 & 106 & 58 & - & 826 \\
\hline \multirow{2}{*}{$\begin{array}{l}\text { Erithacus } \\
\text { rubecula }\end{array}$} & MW & 753 & 1002 & 960 & 898 & 774 & 1176 & 146 & 404 & 620 & 1094 & 7827 \\
\hline & ML & 808 & 1282 & 1281 & 969 & 805 & 1595 & 892 & 744 & 590 & 331 & 9297 \\
\hline \multirow{2}{*}{$\begin{array}{l}\text { Turdus } \\
\text { philomelos }\end{array}$} & MW & & & & & & - & - & & & 275 & 1213 \\
\hline & $\mathrm{M}$ & 381 & 277 & 239 & 81 & 108 & - & - & 148 & 33 & 55 & 1322 \\
\hline \multirow{2}{*}{$\begin{array}{l}\text { Regulus } \\
\text { regulus }\end{array}$} & MW & 1454 & 435 & 879 & 4387 & 3167 & 2409 & 69 & 420 & 522 & 4016 & 17758 \\
\hline & ML & 3932 & 1095 & 3504 & 3181 & 6105 & 8017 & 9633 & 3626 & 1071 & 2025 & 42189 \\
\hline \multirow{2}{*}{$\begin{array}{l}\text { Phylloscopus } \\
\text { trochilus }\end{array}$} & MW & 100 & 208 & 65 & 566 & 214 & 169 & 99 & 248 & 267 & 157 & 2093 \\
\hline & ML & 302 & 813 & 354 & 383 & 173 & 259 & 407 & 103 & 53 & 22 & 2869 \\
\hline Total & & 8125 & 5518 & 7795 & 10955 & 1709 & 1390 & 1590 & 6242 & 3447 & 8028 & 87310 \\
\hline
\end{tabular}




\section{Evaluation of comparability of measurements}

In order to present how the year-to-year variation in the average values of the wing length reflects the actual changes of this trait in the nature, I analysed a relation between the measurements taken simultaneously by different measurers in the same area. The measurements were taken by different ringers at two places (sub-stations), about $0.5 \mathrm{~km}$ apart, during each of the several autumn seasons when these two ringing sites worked at the same time. On the basis of the average wing length calculated for each season at both sub-stations (named as MW and ML) separately, I evaluated the comparability of the measurements collected at these places with the use of Pearson's correlation coefficient. A short distance between the analysed catching sites ensured that the migrants passing the sub-stations represented the same "migration stream" as well as the same composition of populations. However, both sites were a bit differentiated by their habitats (Busse and Kania 1970). A similar method based on the analysis of the correlation coefficient was applied to examine repeatability of the measurements taken at least two times from the same group of individuals (Martin and Bateson 1986, after Harper et al. 1994).

\section{RESULTS}

\section{Comparability of measurements}

The positive correlations between the average wing length of first-year Blackcaps, Garden Warblers, Robins and Song Thrushes measured at two sites (MW and ML) of Mierzeja Wiślana station were generally very strong and highly significant (Fig. 2). For Goldcrests, however, the positive correlation of the average wing length was not significant and for Willow Warblers it was negative but not significant, either.

In the case of all the analysed species, the average wing length measured over the studied periods at those two sub-stations showed no statistically significant differences (Table 2).

Table 2

Average wing lengths for species passing two sites (MW, ML) at Mierzeja Wiślana. Numbers of individuals - see Table 1 .

\begin{tabular}{|l|c|c|c|c|c|c|}
\hline \multirow{2}{*}{} & \multicolumn{2}{|c|}{ Wing length } & \multicolumn{2}{c|}{$S D$} & \multicolumn{2}{c|}{$t$-test } \\
\cline { 2 - 7 } & MW & ML & MW & ML & $t$ & $p$ \\
\hline Sylvia atricapilla & 75.89 & 75.64 & 0.64 & 0.76 & 0.75 & 0.47 \\
\hline Sylvia borin & 78.06 & 78.44 & 0.86 & 0.71 & 1.03 & 0.32 \\
\hline Erithacus rubecula * & 71.59 & 71.98 & 0.70 & 0.62 & 1.29 & 0.21 \\
\hline Turdus philomelos & 116.95 & 116.38 & 1.39 & 1.72 & 0.73 & 0.48 \\
\hline Phylloscopus trochilus * & 65.84 & 66.42 & 0.53 & 0.87 & 1.71 & 0.11 \\
\hline Regulus regulus * & 53.37 & 53.73 & 0.53 & 0.31 & 1.84 & 0.08 \\
\hline
\end{tabular}

* some males have longer wings than females but this can also depend on population (Svensson 1992) 

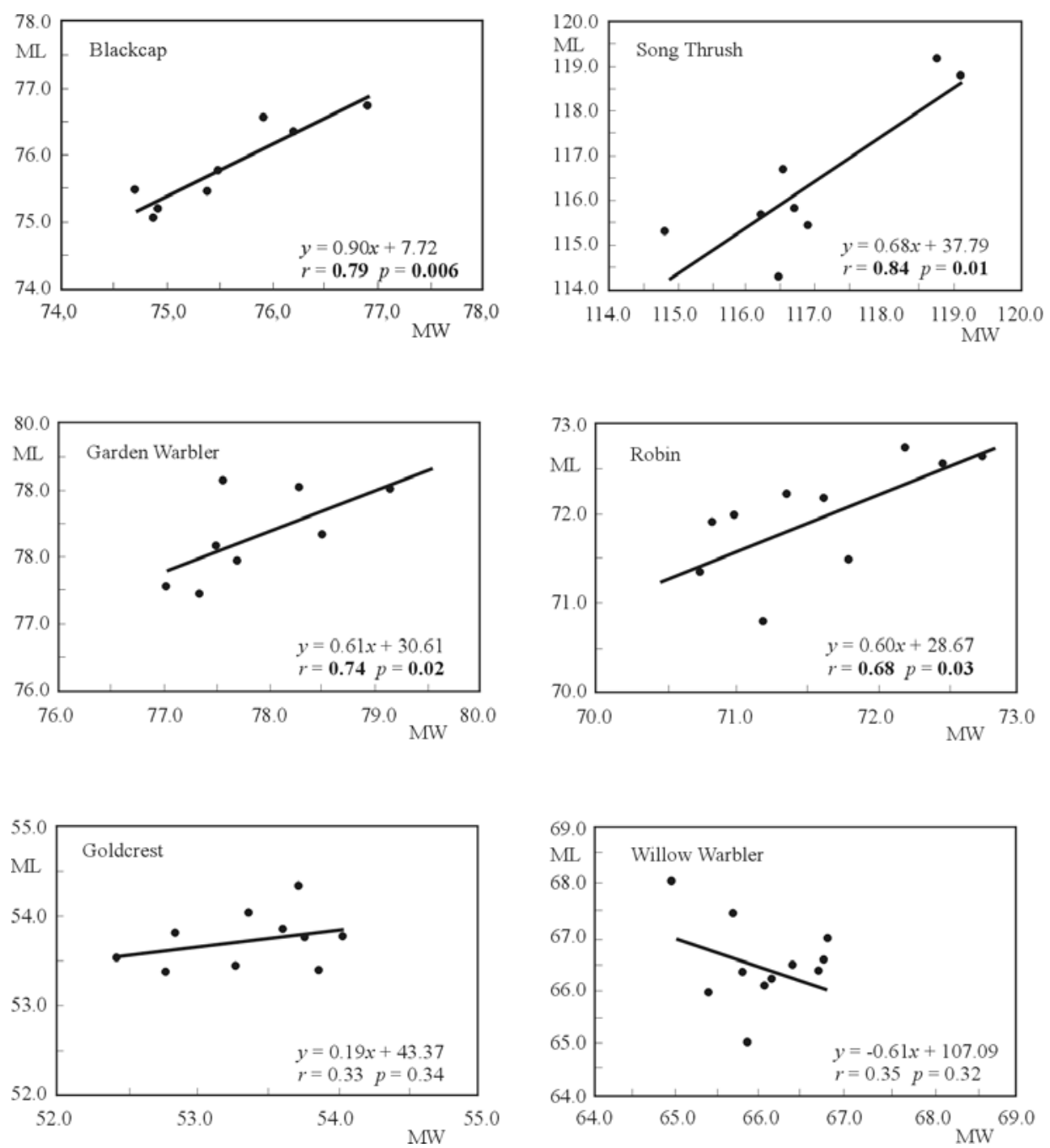

Fig. 2. Relations between the average wing lengths measured at two sub-stations (MW and ML) of Mierzeja Wiślana station. Regression equations, Pearson's correlation coefficients $(r)$ and statistical significance of correlations $(p)$ are given.

\section{DISCUSSION}

A strong and statistically significant correlation in the average measurements taken independently by two ringers at two sites located very close during ten autumn migration seasons indicates that the variation in the average wing length observed over several years can reflect the actual biometric changes of the species/populations passing the study site. The variability of the wing length assessment resulting from the measurements taken by different ringers is generally considered to be low, particularly in birds similar in size to the Garden Warbler, for which a research con- 
ducted in Germany showed the variation of $0 \%$ (Salewski et al. 2010). However, in the case of larger species the variation was as high as $29 \%$ of the total random error variance (Salewski et al. 2010). Furthermore, the authors stated that the variation of measurements caused by different habits of individual measurers had little and insignificant influence on the recorded average annual wing length. In this paper we compare the measurements not for the same group of individuals measured twice by different ringers, but for two independent groups of birds representing the same flying stream. Significant correlations for the Blackcap, Garden Warbler, Robin and Song Thrush give us at least two pieces of important information. The first one is general also for other species and concerns the accuracy of measurements. Despite some potential unknown variation between two compared samples of measurements, the positive correlation for four species mentioned above tells us that data collected by different ringers in the same area are comparable on long-term level and can provide reliable information about the average size of wing. Another information, which can be extracted from the results, is that the appearance of individuals belonging to those species was quite random at compared sites, without any difference or particular habitat preferences between sex groups or populations mixed in the study area. If habitat preferences and/or non-random distribution of the individuals between substations existed, the result of the correlation would be largely affected. This scenario fits the results of Pearson's correlation for the average wing lengths of Goldcrests and Willow Warblers. Especially for the Willow Warbler the negative correlation excludes the influence of different measuring habits of the ringers. It is highly unlikely that this pattern is caused by ringers' customs while it does not occur in other measured species. However, in order to be sure what exactly influences these results, we need some more detailed investigation of segregation mechanism and habitat preferences of these species.

\section{REFERENCES}

Arizaga J., Barba E., Cantó J.L., Cívico J.M., Cortés V., Greńo J.L., Herranz J.M., Monrós J.S., Moreno P., Piculo R., Verdejo J. 2012. The usefulness of biometrics for the study of avian connectivity within Europe a case study with Blackcaps Sylvia atricapilla in Spain. Ardeola 59, 1: 75-91.

Barrett R.T., Peterz M., Furness R.W., Durnick J. 1989. The variability of biometric measurements. Ring. \& Migr. 10: 13-16. DOI: 10.1080/03078698.1989.9676001

Busse P. 1968. Correlative topography - the method of analysis of the population differentiation. Not. Orn. 9, 3: 1-9.

Busse P. 1974. Biometrical methods. Not. Orn. 15, 3-4: 115-126.

Busse P. 1984. Key to sexing and ageing of European Passerines. Beitr. Naturk. Niedersachsens 37, Suppl.

Busse P. 1988. New methods of interpretation of biometrical variability in migrating birds. Not. Orn. 29: 151-192.

Busse P. 1997. Localization of breeding origin of migrants according to biometrical data: the methodological problem. Ring 19, 1-2: 153-168.

Busse P. 1999. Correlative topography by Krigging - a useful method to study intra-group biometrical differentiation. Ring 21, 2: 145-159.

Busse P. 2000. Bird Station Manual. SEEN, Univ. of Gdańsk, Gdańsk. 
Busse P., Kania W. 1970. Operation Baltic 1961-1967. Working methods. Acta orn. 12, 7: 232-267.

Busse P., Maksalon L. 1986. Biometrical variability of Song Thrushes migrating through polish Baltic Coast. Not. Orn. 27: 105-127.

Fiedler W. 2005. Ecomorphology of the external flight apparatus of blackcaps (Sylvia atricapilla) with different migration behavior. Ann. NY Acad. Sci. 1046: 253-263.

Gosler A.G., Greenwood J.J.D., Baker J.K., King J.R. 1995. A comparison of wing length and primary length as size measures for small passerines: A report to the British Ringing Committee. Ring \& Migr. 16, 2: 65-78. DOI: 10.1080/03078698.1995.9674095

Harper D.G.C. 1994. Some comments on the repeatability of measurements. Ring \& Migr. 15, 2: 84-90. DOI: 10.1080/03078698.1994.9674078

Jenni L., Winkler R. 1994. Moult and Ageing of European passerines. Acad. Press, London.

Kovács S., Csörgö T., Harnos A., Fehérvári P., Nagy K. 2010. Change in migration phenology and biometrics of two conspecifis Sylvia species in Hungary. J. Ornithol. 152: 365-373. DOI: 10.1007/s10336-010-0596-7.

Kovács S., Fehérvári P., Nagy K., Harnos A., Csörgö T. 2012. Changes in migration phenology and biometrical traits of Reed, Marsh and Sedge Warblers. Cent. Eur. J. Biol. 7, 1: 115-125. DOI: 10.2478/s11535-011-0101-1.

Lo Valvo F., Lo Verde G., Lo Valvo M. 1988. Relationships among wing length, wing shape and migration in Blackcap Sylvia atricapilla populations. Ring. \& Migr. 9, 1: 51-54. DOI: 10.1080/03078698.1988.9673923

Martin P., Bateson P. 1986. Measuring behaviour: An introductory guide. Cambridge Univ. Press, Cambridge.

Morgan J.H. 2004. Remarks on the taking and recording of biometric measurements in bird ringing. Ring 26, 1: 71-78. DOI: 10.2478/v10050-008-0058-2.

Nowakowski J.J. 2000. Long-term variability of wing length in population of Reed Warbler Acrocephalus scirpaceus. Acta orn. 35: 173-182.

Nowakowski J.J. 2002. Variation of morphometric parameters within the Savi's Warbler (Locustella luscinioides) population in eastern Poland. Ring 24, 2: 49-67.

Pèrez-Tris J., Tellería J.L. 2001. Age-related variation in wing shape of migratory and sedentary Blackcaps Sylvia atricapilla. J. Avian Biol. 32, 3: 207-213.

Pèrez-Tris J., Tellería J.L. 2002. Migratory and sedentary blackcaps in sympatric non-breeding grounds: implications for the evolution of avian migration. J. Anim. Ecol. 71: 211-224.

Salewski V., Hochachka W.M., Fiedler W. 2010. Global warming and Bergmann's rule: do central European passerines adjust their body size to rising temperatures? Oecologia 162: 247-260. DOI: $10.1007 / \mathrm{s} 00442-009-1446-2$

Svensson L. 1992. Identification guide to European Passerines. Stockholm.

Tellería J.T., Carbonell R. 1999. Morphometric variation of five Iberian Blackcap Sylvia atricapilla populations. J. Avian Biol. 30: 63-71.

Van Buskirk J., Mulvihill R.S., Leberman R.C. 2010. Declining body sizes in North American birds associated with climate change. Oikos 119, 6: 1047-1055. DOI: 10.1111/j.1600-0706. 2009.18349.x.

Yom-Tov Y., Yom-Tov S., Wright J., Thorne Ch.J.R., Du Feu R. 2006. Recent changes in body weight and wing length among some British passerine birds. Oikos 112: 91-101.

Zaniewicz G., Busse P. 2008. Autumn migration dynamics and biometrical differentiation of the Dunnock (Prunella modularis) passing the southern Baltic coast. Ring 30, 1-2: 31-54. DOI: 10.2478/v10050-008-0006-1. 